\title{
WC-高クロム鋳鉄系焼結硬質材料の諸特性
}

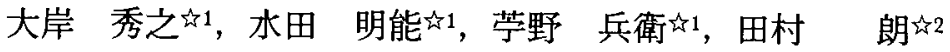 \\ 41 川崎重工業明石技術研究所材料研究部, 干673 明石市川崎町1-1.

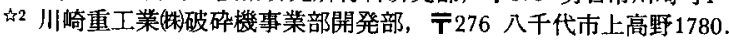

\section{Properties of Sintered WC-(High Chromium Cast Iron) Alloys}

\author{
Hideyuki Ogishi ${ }^{\text {1 }}$, Akiyoshi Mizuta ${ }^{\text {1 }}$, Hyoe Ono ${ }^{\text {ind }}$ and Akira Tamura \\ t1 1 Material Research Department, Akashi Technical Institute, Kawasaki Heavy Industries, Ltd., \\ 1-1 Kawasaki-cho, Akashi 673. Resarch \& Development Department, Crushing Plant Division, \\ Kawasaki Heavy Industries, Ltd., 1780 Kamikoya, Yachiyo 276.
}

Received December 11, 1995

\section{SYNOPSIS}

In the case of partial application of hard materials to wear-resistant components, it is difficult to insert by casting WC-based cemented carbide. In order to solve this problem, we studied WC- (high chromium cast iron) alloys that applied high chromium cast iron instead of cobalt as a binder of WC-based cemented carbide.

We conducted studies on the manufacturing method, mechanical properties, and powder abrasion properties of this WC- (high chromium cast iron) alloy and obtained the following results.

(1) Sound sintered products were obtained by sintering in a pressurized nitrogen atmosphere.

(2) Sintered products with a hardness similar to that of sintered WC-based cemented carbide were obtained.

(3) Sintered products with a flexural strength similar or superior to that of high chromium cast iron were obtained.

(4) Sinterd products with powder injection abrasion properties similar to those of sintered WC-based cemented carbide were obtained.

\section{KEY WORDS}

WC- (high chromium cast iron) alloys, hard materials, manufacturing process, mechanical properties, wear-resistant property

\section{1 緒言}

建設用骨材等の生産に使用される破砕機の部品の摩耗 はアブレイシブ摩耗が主であり，使用部品の耐摩耗性は 硬さに比例していることが実績として認識されている. このことから，高硬度な高クロム鋳鉄等の鉄系耐摩耗鋳 造材料が多用されているか，さらなる摩耗部品の長寿命 化のためには，鉄系材料よりむ硬い硬質材料を摩耗の激 しい簓所に適用することが考えられる，そこで，著者ら は，硬質材料の内で汎用的に用いられているWC-Co系超 硬合金をろう付接合により破砕機の摩耗部品へ部分適用
することを試みたが1), 接合強度とコストを考虑すると鋳 ぐるみにより接合することが望ましい，しかし，WC-Co 系超硬合金の鉄系鋳造材料への鋳ぐるみ接合は困難であ 万.

そこで, 本研究では, WC-Co系超硬合金よりも鋳ぐる み性に優れる材料を開発するため，WC-Co系超硬合金の 結合材であるCoを高クロム鋂鉄に置き換えた WC- 高ク 口ム鋳鉄系硬質材料を焼結法により作製し，その材料特 性についてWC-Co系超硬合金・高ク口ム鋳鉄と比較する ことにより検討を行った．結合材を高クロム鋳鉄に置き 


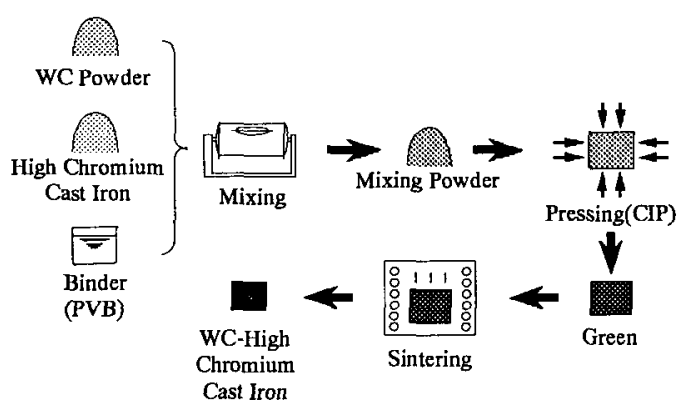

Fig.1 Schematic illustration of the process used to form WC- (high chromium cast iron) alloy.

換えることにより，鋳ぐるみ接合時の濡れ性が改善され る, 熱膨張係数が鉄系材料に近付く等の効果が生じ, 鋳 ぐるみ接合に有利となることが期待できる.

\section{2 蠎結品の作製および試験方法}

\section{1 焼結品の作製}

WC-高クロム鋳鉄系硬質材料焼結品の作製方法をFig.1 に示す，原料粉末としては，市販されている平均粒径 1.5 $\mu \mathrm{m}$ の WC 粉末とガスアトマイズにより作製した粒径 $150 \mu \mathrm{m}$ 以下の高クロム鋳鉄粉末を用いた。高クロム鋳 鉄㸮末の代わりに鋳鉄粉末・炭化クロム粉末・カーボン 粉末等を混合して用いる方法もある ${ }^{2}$ が、ここでは，組 成が Fe-3mass\%C-25mass\%Crである高クロム鋳鉄粉末を 使用した. これら粉末について，Table.1に示すように高 クロム鋳鉄含有量が $10 ， 30 ， 40 ， 50$ mass\% となるように 秤量し，成形用バインダーとしてポリビニルブチラール 樹脂 (PVB) を1.0mass\%添加した. これらに分散媒とし てエチルアルコールを添加してボールミルにより $24 \mathrm{~h}$ 分 散混合し，その後乾燥することにより湿合 (造粒) 粉末 とした. 得られた混合粉末を冷間静水任加压 (CIP) 装置 により $2000 \mathrm{MPa}$ の压力で厚さ $20 \mathrm{~mm} \times$ 幅 $40 \mathrm{~mm} \times$ 長さ $80 \mathrm{~mm}$ の形状に成形した.この成形品について，キャリア

Table.1 Composition of WC-HCCI alloys.

\begin{tabular}{c|c|c}
\multicolumn{2}{c}{ (mass\%) } \\
\hline Designation & WC & HCCl \\
\hline WC-10 HCCI & 90 & 10 \\
WC-30 HCCI & 70 & 30 \\
WC-40 HCCI & 60 & 40 \\
WC-50 HCCI & 50 & 50 \\
\hline
\end{tabular}

HCCI = High Chromium Cast Iron
ガスとして窒素を用いた䨌囲気で脱バインダーを施した 後, 1473 1773K の温度範团で 50K每に真空, 常任空素 ガス，または，加圧 (0.9MPa) 室素ガス雾囲気中で2h の 焼結を行った。このようにして得られたWC-高クロム鋳 鉄系硬質材料焼結品（以下、WC-HCCI と記す）について， 高クロム鋳鉄（組成： Fe-3mass\%C-25mass\%Cr）と同様の 熱処理（焼準：1323K 空冷，焼戻 : 693K 空冷 ${ }^{3)}$ を実施 した後, 材料特性調查 (ミクロ組䅧観察, 比重測定, 硬 さ測定，抗折力試験，衝撃試験，摩耗試験〉を行った.

なお，比較材としてはWC-10mass\%Coの超硬合金およ び鋳造により作製した Fe-3mass\%C-25mass\%Cr の高クロ ム鋳鉄を用いた。

\section{2,2 試験方法}

楛結品について，光学顕微鏡によるミクロ組織観察， アルキメデス法による密度測定，および，ロックウェル (Cスケール)硬さ測定を行った.なお，ミクロ組䅧観察 では，焼結性を確認するために腐食液は使用せずに空孔 の観察を行った.

厚さ $4 \mathrm{~mm} \times$ 幅 $8 \mathrm{~mm} \times$ 長さ $30 \mathrm{~mm}$ の形状に加工した試 験片について 3 点曲げにより抗折力試験を行った.

厚さ $10 \mathrm{~mm} \times$ 幅 $10 \mathrm{~mm} \times$ 長さ $55 \mathrm{~mm}$ の形状に研削加工 した試験片（ノッチレス）についてシャルピー衝撃試験 (30kg-m)を行った.

摩耗試験は，Fig.2 に示すような粉体噴射摩耗試験を 行った. 試験片形状は厚さ $3 \mathrm{~mm} \times$ 幅 $25 \mathrm{~mm} \times$ 長さ $25 \mathrm{~mm}$ とし, 試験片端部の異常摩耗が生じないように試験片の 周りにはコム製のダミーを取り付けた. 枌体にはケイ砂 を用い，試験条件は試験片との衝突角度を $35^{\circ}$ ，空気压 を $50 \mathrm{kPa}$ ，試験時間を $2 \mathrm{~h}$ とした，粉体噴射摩耗試験によ る摩耗体積隇量を測定して耐摩耗性を評価した。

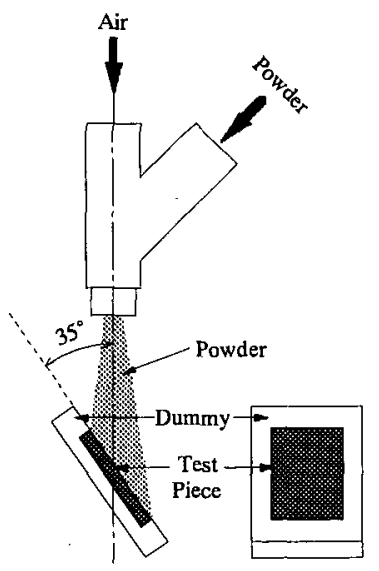

Fig.2 Schematic illustration of the wear test. 


\section{3 試験結果と考察}

\section{$3 \cdot 1$ ミク口組織}

良好な WC-HCCI を得るための焼結条件を選定するた めに, 前記各条件で焼結を行った焼結品についてミクロ 組織観察を行った，一例としてPhoto.1に，WC-30mass\% HCCIについて常圧窒素ガス雾囲気中において 1473〜 1773K で焼結を行った焼結品のミク口組織を示す．この ように，常圧窒素ガス雾囲気中では焼結温度を換えても 空孔が観察され，良好な焼結品を得ることはできなかっ た. Photo.2に示すように, 真空雾囲気における焼結でも 同様の結果であったが, $0.9 \mathrm{MPa} の$ 加圧窒素雾囲気におい て焼結を行ったところ, 空孔の非常に少ない良好な焼結 品を得ることができた. Photo.3に，加圧窒素雾囲気にお いて焼結を行った WC-10，30，40，50 mass\%HCCIのミ ク口組織を示す，焼結温度はそれぞれ $1723 \mathrm{~K} ， 1673 \mathrm{~K}$, 1573K，1473Kである. この結果からわかるように, WC30,40mass\% HCCIについては良好な焼結品を得ることが
できたが，WC-10，50mass\%HCCIについては，加圧窒素 雾囲気で焼結を行っても良好な焼結品が得られなかった。 この原因として, wC-10mass\%HCCI の場合は, 結合材含 有量が少ないために液相が焼結品全体に行き渡らなかっ たこと，WC- $50 \mathrm{mass} \% \mathrm{HCCl}$ の場合は，共晶点近傍組成て ある結合材の含有量が多く焼結温度範囲が狭いため最適 な条件で処理ができていないことがそれぞれ考えられる.

このようにして良好な焼結品を得ることができたWC30, 40mass\%HCCIについて，以下の特性特性試験を実施 した.

\section{2 材料特性試験}

Table.2に，超硬合金（WC-10mass\%Co）および高クロ 么鋳鉄（Fe-3mass\%C-25mass\%Cr) と比較した, WC-30, $40 \mathrm{mass} \% \mathrm{HCCI}$ の材料特性試験結果を示す.

密度については, WCの密度 $\left(15.7 \times 10^{3} \mathrm{~kg} / \mathrm{m}^{3}\right)^{4)}$ に比 へて高クロム鋳鉄の密度 $\left(7.5 \times 10^{3} \mathrm{~kg} / \mathrm{m}^{3}\right)$ が小さいため, WC-HCCIの密度は高クロム鋳鉄含有量が増加するほど減 少している.

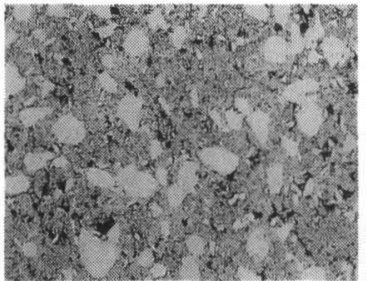

$1473 \mathrm{~K}$

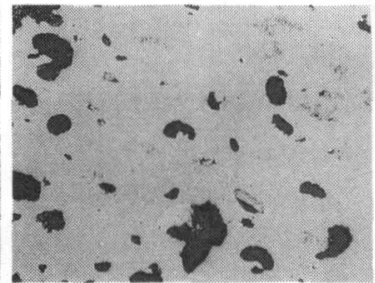

$1573 \mathrm{~K}$

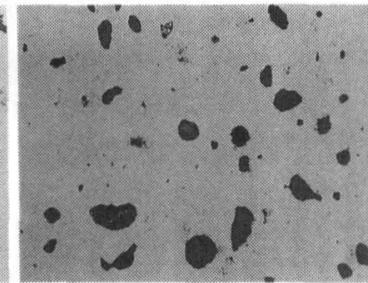

$1673 \mathrm{~K}$

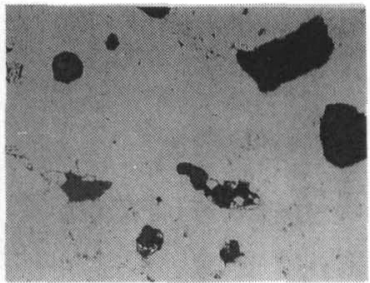

$1773 \mathrm{~K}$

Photo.1 Microstructures of WC-30mass\% HCCI sintered at $1473 \mathrm{~K}$ to $1773 \mathrm{~K}$ in nitrogen atmospher.

$100 \mu \mathrm{m}$

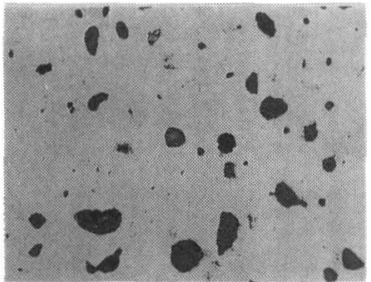

Nitrogen

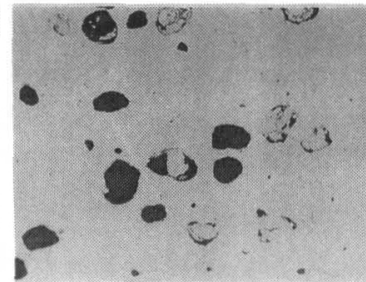

Vaccum

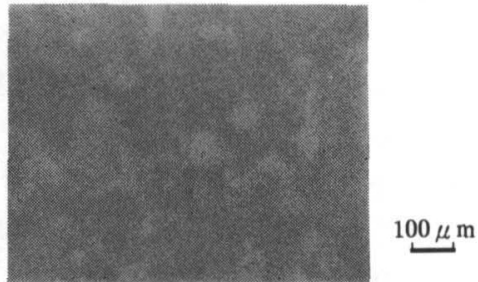

Nitrogen $(0.9 \mathrm{MPa})$

Photo. 2 Microstructures of WC-30mass\% HCCI sintered at $1673 \mathrm{~K}$ in nitrogen, vaccum and nitrogen (0.9MPa) atmospheres.

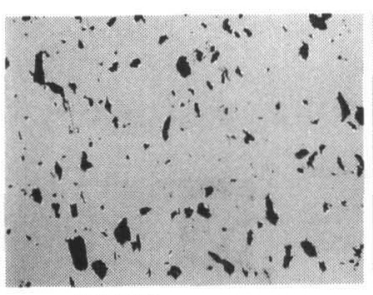

WC-10mass\%HCCI

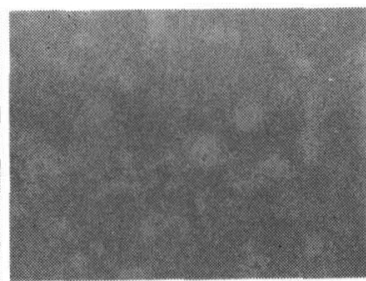

WC-30mass\%HCCI

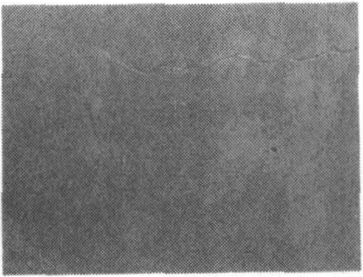

WC-40mass\%HCCI

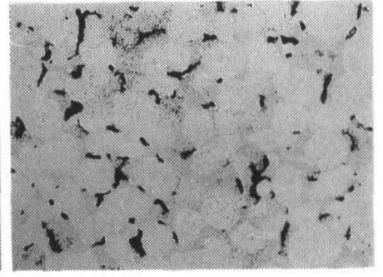

WC-50mass\%HCCI

$100 \mu \mathrm{m}$

Photo.3 Microstructures of WC-10,30,40,50mass\% $\mathrm{HCCI}$ sintered in nitrogen (0.9MPa) atmosphere. 
Table.2 Mechanical properties of WC-30,40mass\% $\mathrm{HCCl}$, high chromium cast iron and WC-10mass \%Co.

\begin{tabular}{c|c|c|c|c}
\hline $\begin{array}{c}\text { Composition } \\
\text { [mass\%] }\end{array}$ & $\begin{array}{c}\text { Density } \\
{\left[\times 10^{3} \mathrm{~kg} / \mathrm{m}^{3}\right]}\end{array}$ & $\begin{array}{c}\text { Hartness } \\
\text { (HRC) }\end{array}$ & $\begin{array}{c}\text { Flexural Strength } \\
\text { [MPa] }\end{array}$ & $\begin{array}{c}\text { Impart Va]ue } \\
{\left[\times 10^{4} \mathrm{~J} / \mathrm{m}^{2}\right]}\end{array}$ \\
\hline WC-30HCCI & 11.7 & 74 & 740 & 3 \\
WC-40HCCI & 11.0 & 71 & 690 & 3 \\
\hline High Chromoum Cast Iron & 7.5 & 64 & 670 & $3 \sim 5$ \\
WC-10Co & 14.6 & 75 & 2930 & 10 \\
\hline
\end{tabular}

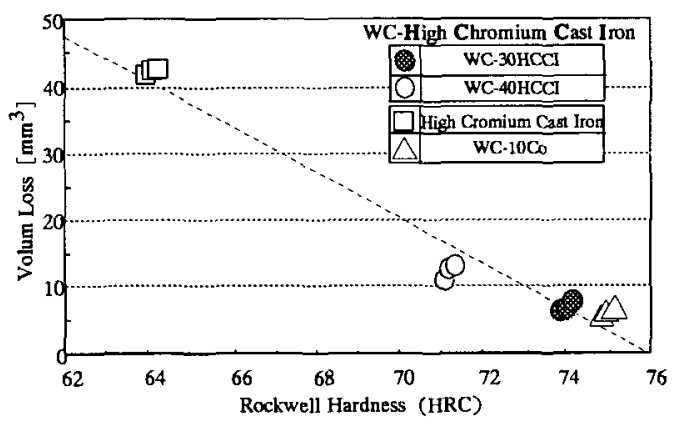

Fig.3 Results of the wear test.

硬さについては，硬質なWCの含有量が多いWC-30 mass\%HCCIの方がWC-40mass\%HCCIよりも硬い.しか し, 超硬合金と比較すると，超硬合金がWCを $90 \mathrm{mass} \%$ 含有しているのに対してWC-30mass\%HCCIのWC含有量 が70mass\%と少ないにもかかわらず，同等の硬さを有し ている.これは, WC-HCCIの結合材である高クロム鋳鉄 (HV800) が超硬合金の結合材であるCo (HV125)よりも 硬いことに起因していると思われる.

抗折力については，WC-30,40mass\%HCCI ともに高ク ロム鋳鉄と同等以上の值を有している.しかし，超硬合 金と比べると䄪1/4と小さな值を示している. この原因と しては，WC-30，40mass\%HCCI が結合材として高クロム 鋳鉄を使用しているために硬くて脆いクロム炭化物を多 量に含んでいること; $\mathrm{Fe}$ 基の合金である高クロム鋳鉄に 対するWCの固溶度がCoに対するそれと比へてかなり小 さく ${ }^{5}$ WC と高クロム鋳鉄との結合力が小さいことが考 えられる.

衝轵値については、WC-30，40mass\%HCCI ともに高ク ロム鋳鉄と同等の値を有しているが、超硬合金と比べる と小さな値を示している。これも、抗折力と同じ原因に よるものと思われる。

\section{3 摩耗試験}

FIg.3に粉体噴射摩耗試験による摩耗体積減量之硬さの 関係を示す. WC-30mass\%HCCl は超硬合金と同等の耐摩 耗性を示しており，高クロム鋳鉄と比べて良好な耐摩耗 性を示していることがわかる.WC-HCCIは, 超硬合金と 比へると機械的性質が劣るが，粉体による摩耗のように 強度的な負担のかからない摩耗形態に対しては，超硬合 金並の耐摩耗性を発揮することがわかった．また，粉体 に対する耐摩耗性については硬さ依存性があり，硬い材 料はと耐摩耗性が高いことが確認された。

\section{4 まとめ}

WC-Co 系超硬合金の結合材であるCoを高クロム鋳鉄 に置き換えたWC-高クロム鋳鉄系硬犋材料焼結品を作製 してその諸特性を調查することにより，以下の結果を得 ることができた。

( 1 ) 真空および常压窒素雾囲気における狫結では空孔が 多く健全な焼結品が得られなかったが, 加圧窒素雲团気 において焼結を行うことにより空孔の非常に少ない焼結 品を得ることができた。

（2）超硬合金（WC-Co）と比べてWC含有量が少ないに もかかわらず，高い硬度を有する燒結品を得ることがで きた.これは、結合材である高クロム鋳鉄がCoよりも硬 いためである.

（3）焼結品の抗折力は高クロム鋳鉄と同等以上である が，超硬合金の約 $1 / 4$ であった。これは，硬くて脆いクロ 么炭化物を多量に含有していることと, WCのFeに対す る固溶度が小さいことに起因していると思われる。

(4)ケイ砂による粉体噴射摩耗試験の結果では, 焼結品 は超硬合金と同等の耐摩耗性を有しており，また，耐摩 耗性の硬さ依存性が確認された.

\section{文献}

1) 大岸秀之, 芦野兵衛, 田村朗, 野見山文博, 森司: 川 崎重工技報，121 (1994) 13 .

2) 坂口茂也，今里州一，伊藤普，中村良三：粉体および 粉沫治金, 8 (1989) 908.

3) 田村朗，野見山文博 : 鋳物，10 (1995) 696.

4) P.Schwarzkopf, R.Kieffer : Cemented Carbides (1960), Macmillan

5) F.W.Glaser : Met.Progr.,67 (1955) 77. 